\title{
Influence of laser therapy on the dynamic formation of extracellular matrix in standard second degree burns treated with bacterial cellulose membrane
}

\author{
Patricia Keler Freitas Machado Vasconcellos ${ }^{\mathrm{a}}$, Manuela Pimentel Nóia ${ }^{\mathrm{a}}$, \\ Isabele Cardoso Vieira De Castro ${ }^{\mathrm{a}, \mathrm{b}}$, Jean Nunes dos Santos ${ }^{\mathrm{a}}$, Antonio Luiz B. Pinheiro ${ }^{\mathrm{b}}$, \\ Aparecida Maria Cordeiro Marques ${ }^{b}$, Eduardo Antonio Gonçalves Ramos ${ }^{\mathrm{c}}$, \\ Clarissa Gurgel Rocha, ${ }^{\mathrm{a}, \mathrm{c},}$
}

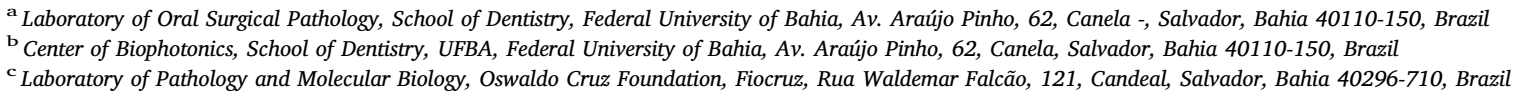

\section{A R T I C L E I N F O}

\section{Keywords:}

Second-degree burns

Laser

Bacterial cellulose membrane

Tissue repair

\begin{abstract}
A B S T R A C T
The present study aims to assess the influence of Aluminum-Gallium-Indium-Phosphide laser (AlGaInP laser, $\lambda=660 \mathrm{~nm}$ ), whether or not in association with the application of a membrane of bacterial cellulose (Nexfill ${ }^{\mathrm{TM}}$ ), during recovery from induced second-degree burns at the dorsum of Wistar rats. (Rattus norvegicus, Wistar). Forty-eight animals have been distributed into four groups: Control (burns remained untreated), Group I (lasertreated), Group II (treated with Nexfill), and Group III (laser + Nexfill ${ }^{\mathrm{TM}}$ ). In addition to a morphological analysis, immunohistochemical analysis has been performed for type I collagen, type III collagen, fibronectin, and laminin. The Fisher's Test was used to assess differences among groups ( $\mathrm{p}<0,05)$. A larger amount of collagen type III was observed in Control, Group II and Group III when compared with Group I ( $p<0,05$ ). Group I and Group III have shown a greater collagen deposition when compared with Group II ( $p<0,05)$, but the amount of collagen was similar in Group I, Group III, and Control. Group III has shown larger fibronectin amounts in comparison with Group II ( $\mathrm{p}<0,05)$. As regards laminin, Group I has shown a predominant discontinuity pattern on the basal lamina in comparison with Control, Group II, and Group III ( $p<0,05)$. It is concluded that in this current study the laser when used alone (Group I) hasn't influenced collagen deposition neither has it acted on fiber pattern (fibril and/or reticular). Moreover, laser application hasn't accelerated the repair of wounds caused by inflicted second-degree burns.
\end{abstract}

\section{Introduction}

Burns are one of the commonest types of trauma facing human beings [1] and, regardless of a worldwide decline in the death rate arising from burns, associated non-fatal sequelae frequently tend to lead to permanent impairments [2]. In such injuries, the clinical treatment and repair process are dependent on the extent and depth of the damage. In many cases, burns can immediately be treated by means of autologous graft - which promptly leads to a permanent and satisfactory wound closure. However, in many situations this type of treatment appears to be impossible or unlikely to succeed, for instance in cases of infected or severely extensive wounds [3,4].

Therefore, temporary wound dressings are deemed necessary in order to maintain the function of the wound, reduce infection, relieve the pain and metabolic stress, in addition to providing blood supply and protection against trauma $[3,5,6]$. In light of this fact, research into wound dressings has advanced the production of a wide range of synthetic and biological dressings for wound care and management [7]. Options readily available include the bacterial cellulose biomembrane, a biosynthetic polymer that provides optimum conditions for epidermal regeneration owing to its nanomorphological characteristics, protection against infection and ability to hold water; in addition, it enables the transfer of medicines into the wound [8-10].

The influence of laser on wound healing has recently motivated a number of experimental studies - some of which drawing attention to biostimulation and healing properties [11-15]. Laser therapy triggers cellular processes and a response from the vascular system which appear to have a direct impact on tissue repair [16]. As a result, research on the effects of photobiomodulators on burns has become increasingly common [1,17-19] and fairly recently scholarly papers have addressed

\footnotetext{
* Corresponding author at: Laboratory of Oral Surgical Pathology, School of Dentistry, Federal University of Bahia, Av. Araújo Pinho, 62, Canela, Salvador, Bahia 40110-150, Brazil.

E-mail address: gurgel.clarissa@gmail.com (C.G. Rocha).
} 
an associated use of laser and occlusive dressings [20,21]. Nonetheless, substantial evidence is still lacking as regards the bacterial biocellulose membrane in association with laser use in the healing of second-degree burns.

Given the above considerations and also taking into account the perceived advantages of bacterial cellulose membrane and laser use, it is arguably valid to undertake research as to assess possible effects of a combined use of both therapies for burn treatment, ensuring faster, more efficient, and less painful healing with better functional and cosmetic results.

\section{Materials and Methods}

\subsection{Sample Selection}

A total of forty-eight male, albino, young, healthy rats (Rattus norvegicus, Wistar) aged two months and weighing $150 \mathrm{~g}-200 \mathrm{~g}$ were randomly selected from the Laboratory Vivarium at Gonçalo Moniz Research Center (FIOCRUZ, Bahia, Brazil). The animals were housed individually at $22^{\circ} \mathrm{C}$ under a light/dark cycle established as $12 \mathrm{~h}$ light on, with ready access to Labina rat feed and water ad libitum. The rats were distributed into four groups of 12 animals as follows: Control, Group I (laser radiation), Group II (Nexfill ${ }^{\mathrm{TM}}$ bacterial cellulose membrane), and Group III (laser radiation associated with the application of Nexfill $^{\mathrm{TM}}$ membrane).

\subsection{Ethical Considerations}

In order for this research to be conducted, prior approval was received from the Committee for Experimentation and Animal Use (CEUA) at Gonçalo Moniz Research Center (CPqGM-FIOCRUZ - BA), under the Protocol 008/2007. Adherence to ethical principles was ensured for the performance of experimental use of animals as well as their vivisection for academic-scientific purposes.

\subsection{Induction of Standard Second-Degree Burn Injury}

The animals were anesthetized with $75 \mathrm{mg} / \mathrm{kg}$ Ketamine and $10 \mathrm{mg} /$ $\mathrm{kg}$ Xylazine intraperitoneal injection. Next, an area measuring $2 \times 2 \mathrm{~cm}$ was depilated at the dorsum of the animal so that antisepsis was performed with polyvinylpyrrolidone-iodine solution. Infliction of burn wounds has been performed in accordance with Meyer and Silva's modified technique [22]. To this end, a brass bar with a cube-shaped tip was pre-heated in boiling water for $1 \mathrm{~min}$ and subsequently placed on the skin of the animal for $0.5 \mathrm{~s}$, and timed with a digital timer. Once the surgery procedure completed, an oral dose of Sodium Dipyrone was administered to each and every rat according to their weight. The epidermis on the wound area was removed with a scalpel blade no. 15 as to expose the subcutaneous tissue. This was a necessary for the application of the Nexfill ${ }^{\mathrm{TM}}$ cellulose membrane on the superficial dermis.

\subsection{Laser Radiation Protocol}

The animals allocated in Group I and Group III received radiation from a red laser AlGaInP ( $\lambda=660 \mathrm{~nm}, 40 \mathrm{~mW}, \varnothing=4 \mathrm{~mm}^{2}, t=125 \mathrm{~s}$ ) with a SAEF (Spatial Average Energy Fluence) at $20 \mathrm{~J} / \mathrm{cm}^{2}$ split into four points of $5 \mathrm{~J} / \mathrm{cm}^{2}$ each $[19,23]$. Controls were sham-irradiated. Irradiation was performed immediately after the infliction of burns and every $48 \mathrm{~h}$ until one day before the death of the animals, which occurred $24 \mathrm{~h}, 3$ days, 7 days, and 14 days later in a $\mathrm{CO}_{2}$ chamber. A summary of the laser parameters used on the study is depicted on Table 1.

\subsection{Morphological and Immunohistochemical Analysis}

Following death, the tissue fragments were removed from the
Table 1

Summary of the laser parameters used on the study.

\begin{tabular}{ll}
\hline Parameters & Laser \\
\hline Wavelength (nm) & 660 \\
SAEF $\left(\mathrm{J} / \mathrm{cm}^{2}\right)($ per session) & 20 \\
Energy density $\left(\mathrm{J} / \mathrm{cm}^{2}\right)$ (per point) & $5 \mathrm{~J} / \mathrm{cm}^{2}$ \\
Power output $(\mathrm{mW})$ & 40 \\
Illuminated area $\left(\mathrm{cm}^{2}\right)$ & 4 \\
Mode & $\mathrm{CW}$ \\
Spot $\left(\mathrm{cm}^{2}\right)$ & 0.04 \\
Intensity $\left(\mathrm{mW} / \mathrm{cm}^{2}\right)$ & 1.000 \\
Exposure time $($ per session) & $125 \mathrm{~s}$ \\
\hline
\end{tabular}

wound area, placed in formalin at $10 \%$ and routinely processed for staining with hematoxylin-eosin, picrosirius for fibrosis and orcein analysis of elastic fibers. Histological sections were morphologically diagnosed in a candid fashion by an experienced pathologist by light microscopy (Zeiss Axioskop) and the treated groups were compared to the control group (no treatment). The inflammatory infiltrate was classified as absent, predominantly polymorphonuclear, predominantly mononuclear, or mixed. Inflammatory infiltration and edema (if present), the presence of adipocytes in the dermis, and production of collagen and elastic fibers were semi-quantitatively marked as absent (0), mild $(+)$, moderate $(++)$ and strong $(+++)$.

The deposition of the extracellular matrix was assessed by immunohistochemistry using a polymer system (AdvanceTM, Dako Corporation) and antibodies directed against the following proteins: collagen types I and III, fibronectin, and laminin (Table 2).

In order to undertake immunostaining animals dead at $24 \mathrm{~h}$ of the experiment were excluded. Collagen I and III were analyzed in order to calculate the percentage of wound covering, by taking into consideration only the papillary dermis (score $0: 0-10 \%$ coverage; score 1 : 11-30\%; score 2: $31-60 \%$ and score $3:>60 \%$ ) and the fiber pattern (reticular, fibril, or mixed). The fibers were regarded as reticular when they appeared to be only partially stained, and fibril when stained in its entirety.

For fibronectin protein, the analysis was performed by using the following criteria: presence of protein underlying the epithelial basement membrane and distribution in the papillary dermis in the focal and dispersed patterns; percentage of wound covering (score 1: up to $30 \%$, score $2: 31$ to $60 \%$, and score $3:>60 \%$ of coverage) and pattern of the fibers (reticular, fibril, or mixed). For this protein, the animals were also considered for three days.

Analysis of laminin was made according to its location in the subepithelial basement membrane or vascular basement membrane. Criteria for both stainings: percentage for staining $(\leq 50 \%$ and $>$ $50 \%$ ), continuity (continuous and discontinuous), and thickness (thin, thick, or mixed).

\subsection{Statistical Analysis}

Data were compiled into an Excel ${ }^{\mathrm{TM}}$ (Microsoft) Spreadsheet and then transferred to the Graph Pad Prism Version 5.0, Software Inc. (La Jolla, California, USA). For comparison and assessment of statistical differences among the experimental groups, the Fisher's non-parametric test was applied considering the value of $\mathrm{p}<0.05$.

\section{Results}

In the morphological analysis, acute, dense inflammatory infiltrate was present in the Control Group, in addition to an edema within $24 \mathrm{~h}$. As early as seven days, the specimens showed complete wound healing, with no inflammatory infiltrate and it has been noted an increase in collagen fibers within seven to 14 days. Group I has shown within $24 \mathrm{~h}$ dense, acute inflammatory infiltrate, so remaining until the seventh day 
Table 2

Clone, manufacturer, dilution, antigen retrieval, and incubation time of antibodies.

\begin{tabular}{|c|c|c|c|c|c|}
\hline Antibody & Clone & Manufacturer & Dilution & Antigen retrieval & Incubation time \\
\hline Fibronectin & Polyclonal & Abcam & $1: 1000$ & NO RETRIEVAL & $20^{\prime}$ \\
\hline Laminin & Polyclonal & Dako & $1: 100$ & Trypsin $1 \% 30^{\prime}$ at $37^{\circ} \mathrm{C}$ & $1 \mathrm{~h}$ \\
\hline Collagen I & $5 \mathrm{D} 8$ & Abbiotec & $1: 400$ & Trypsin $1 \% 30^{\prime}$ at $37^{\circ} \mathrm{C}$ & $1 \mathrm{~h}$ \\
\hline Collagen III & Polyclonal & Abbiotec & $1: 300$ & Trypsin $1 \% 30^{\prime}$ at $37^{\circ} \mathrm{C}$ & $1 \mathrm{~h}$ \\
\hline
\end{tabular}

\section{3 days}

A
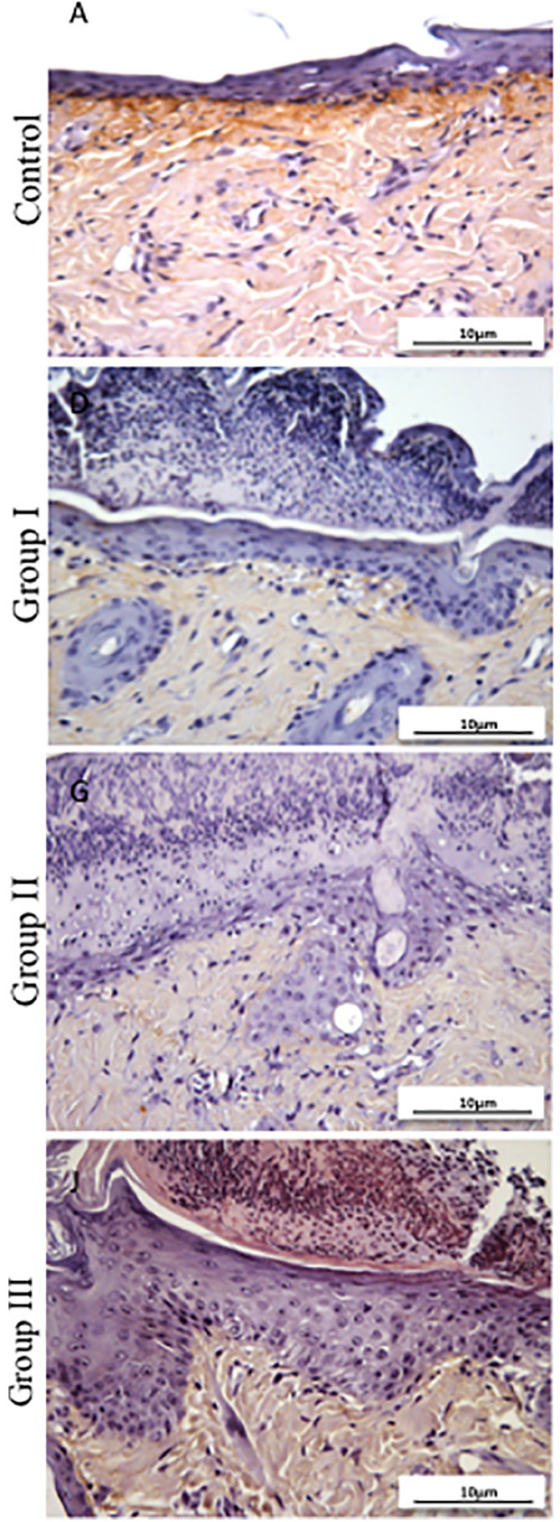

7 days

8
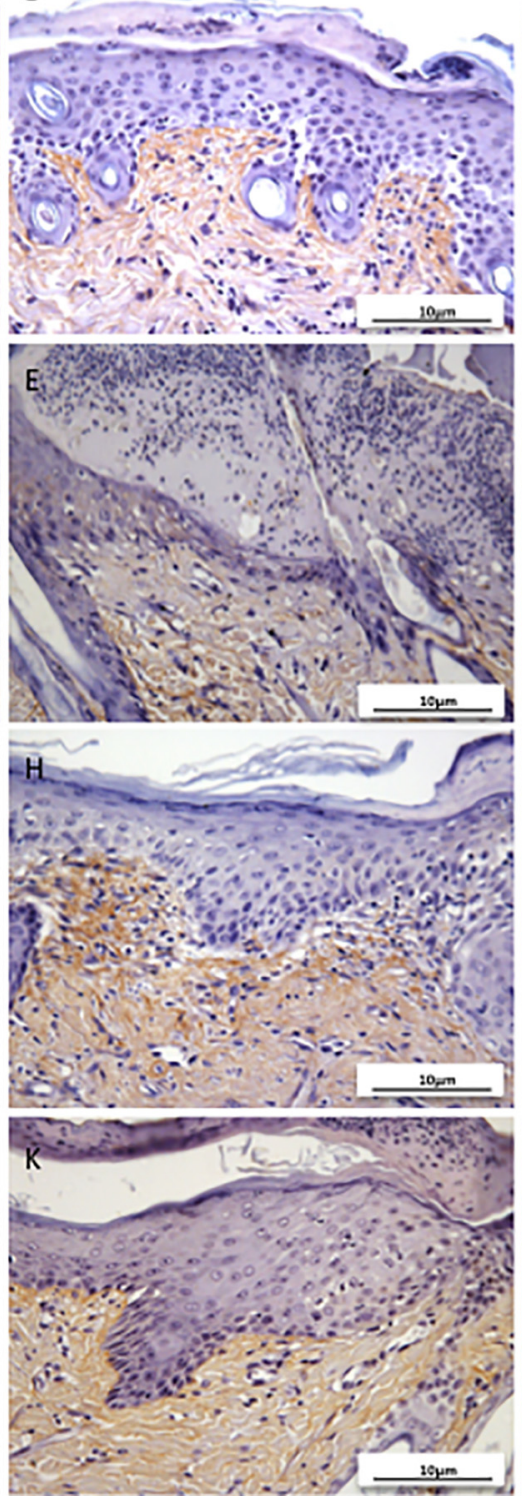

14 days
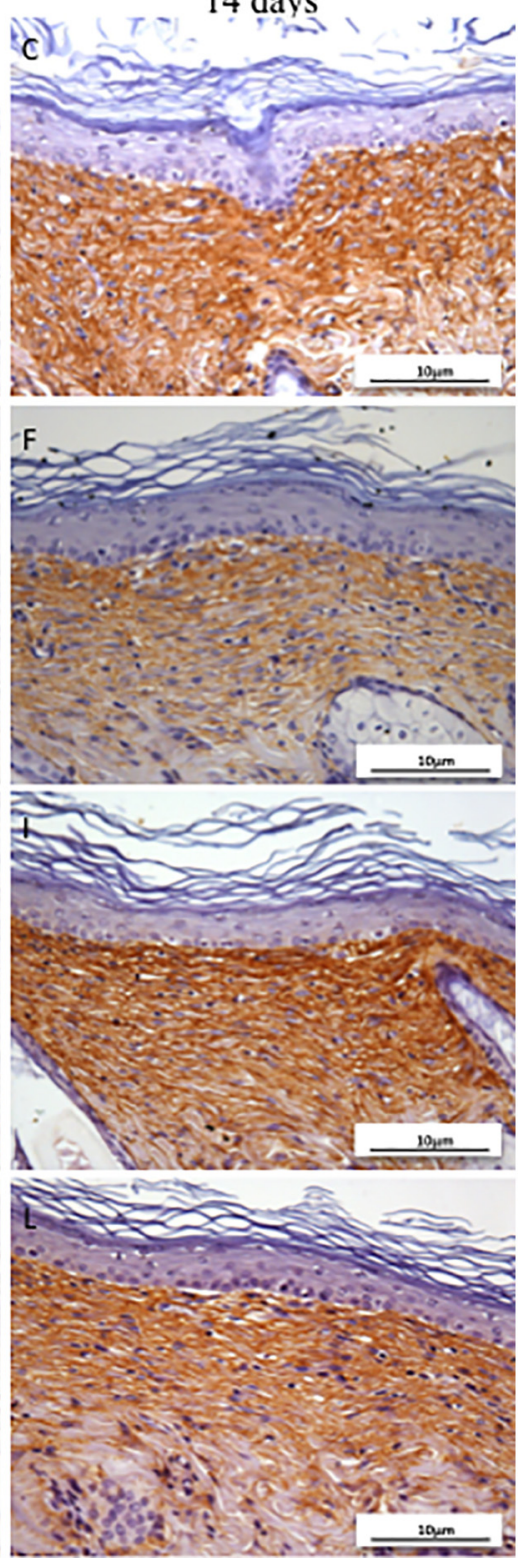

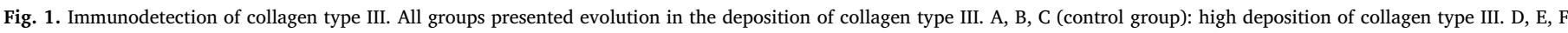

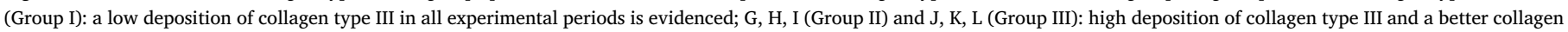
fiber parallelism is observed on the 14th day.

of the experiment. At 14 days, this group still had chronic or mixed inflammatory infiltrate and edema in $75 \%$ of specimens.

During the experimental time of $24 \mathrm{~h}$, Group II has shown acute inflammatory infiltrate which evolved to mixed, and a mild edema on the seventh day with increased expression of collagen fibers. There was a decrease in elastic fibers in $75 \%$ of the specimens in this group on the 14th day, with strong staining of collagen fibers and absence of inflammatory infiltrate. Group III had moderate acute inflammatory infiltrate at $24 \mathrm{~h}$. There was still edema after three days, disappearing completely on the seventh day. Between seven to 14 days it has been noted an increase in collagen fibers and a decrease in elastic fibers.

In order to make an assessment of immunostaining of collagen I and III, fibronectin and laminin (Figs. 1-4), the groups were statistically compared regardless the experimental time and there was a higher amount of type III collagen in the Control, Group II, and Group III when compared to Group I ( $\mathrm{p}<0.05$ ). As far as type I collagen is concerned, 

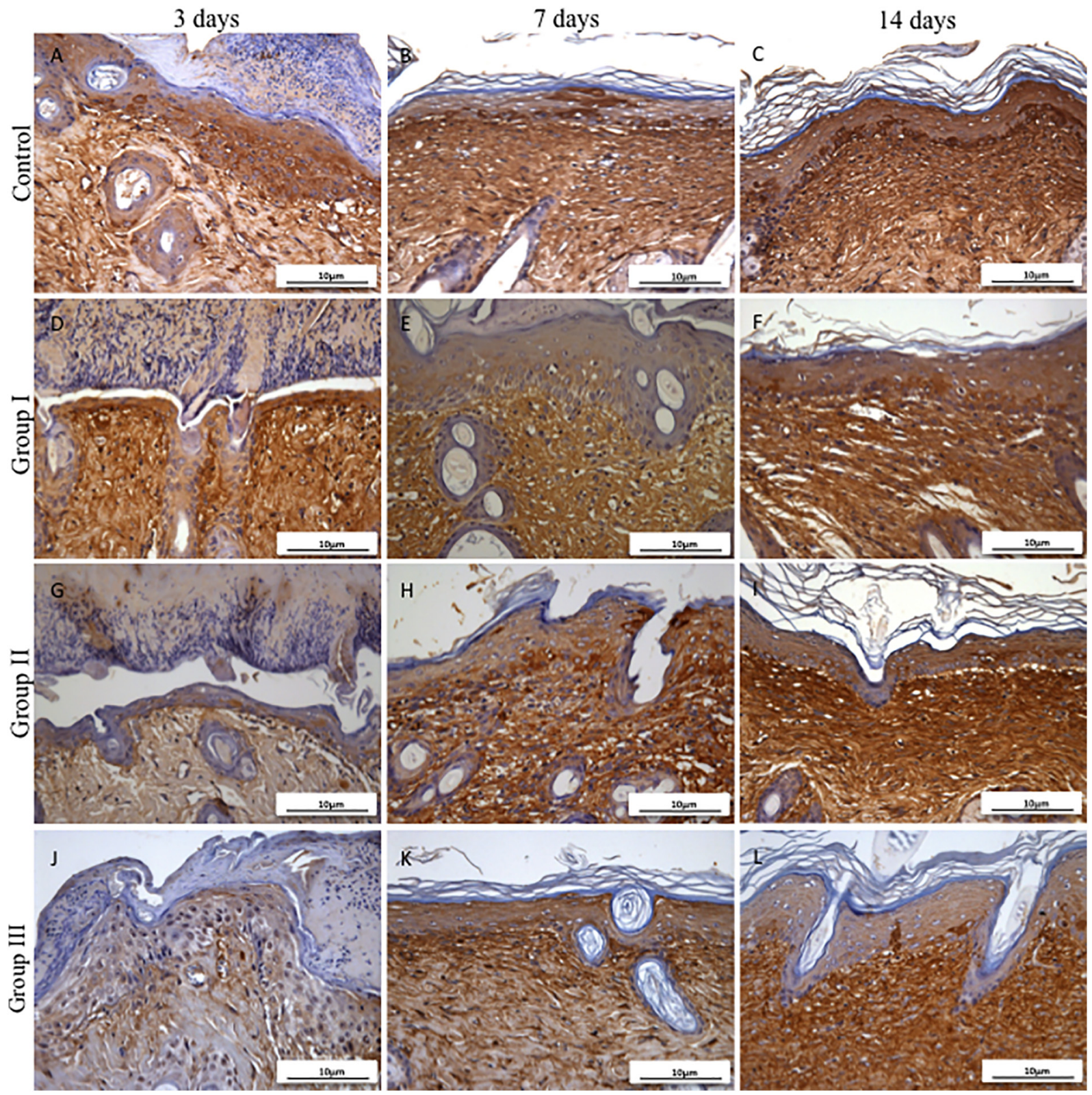

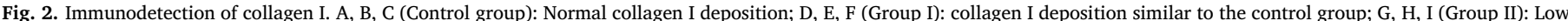

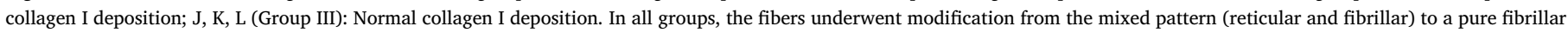
pattern. A greater collagen fiber parallelism in the 14th day in all the experimental groups is observed.

Groups I and III had a higher deposition of this protein as compared to Group II and this difference was statistically significant ( $\mathrm{p}<0.05)$. However, there was no statistically significant difference in collagen I deposition among Group I, Group III, and Control. Furthermore, a better filling by fibronectin has been described in Group III when compared with Group II ( $<$ 0.05) (Fig. 5).

As regards the laminin pattern on the subepithelial basement membrane, Group I has shown a pattern of discontinuity and this result was significant when this group was compared with Control, Group II, and Group III ( $p<0.05)$. The laminin expression in the basal membrane of vessels was similar in all groups during all trials of this experiment: $>50 \%$, continuous and thick (Table 3 ).

\section{Discussion}

It has been investigated in this study the extent to which a therapy employing Aluminum-Gallium-Indium-Phosphide laser of $\lambda=660 \mathrm{~nm}$, whether or not in association with Nexfill ${ }^{\mathrm{TM}}$ bacterial cellulose membrane, could lead to better healing of second-degree burns using an animal model for research. For this analysis, morphological analysis and immunohistochemical technique were performed in order to assess the formation of the extracellular matrix by means of the deposition of matrix proteins which play key roles in the skin repair process: types I and III collagens, fibronectin, and laminin.

Acquisition of a burn model for this study is similar to the protocol used by Bayat et al. [17] to cause a second-degree burn. However, there are reports in the literature which reproduced third-degree burns on their experiments $[1,19,24]$ whereas there is research which makes no reference to the depth of injury inflicted [18,21,25]. This variety of methodologies used has contributed to some difficulty in finding comparable and results among scholarly sources reproducible results among scholarly sources.

Traditionally, the assessment of collagen type I and type III provides a clear sign of improvement in the healing process, given that in the 


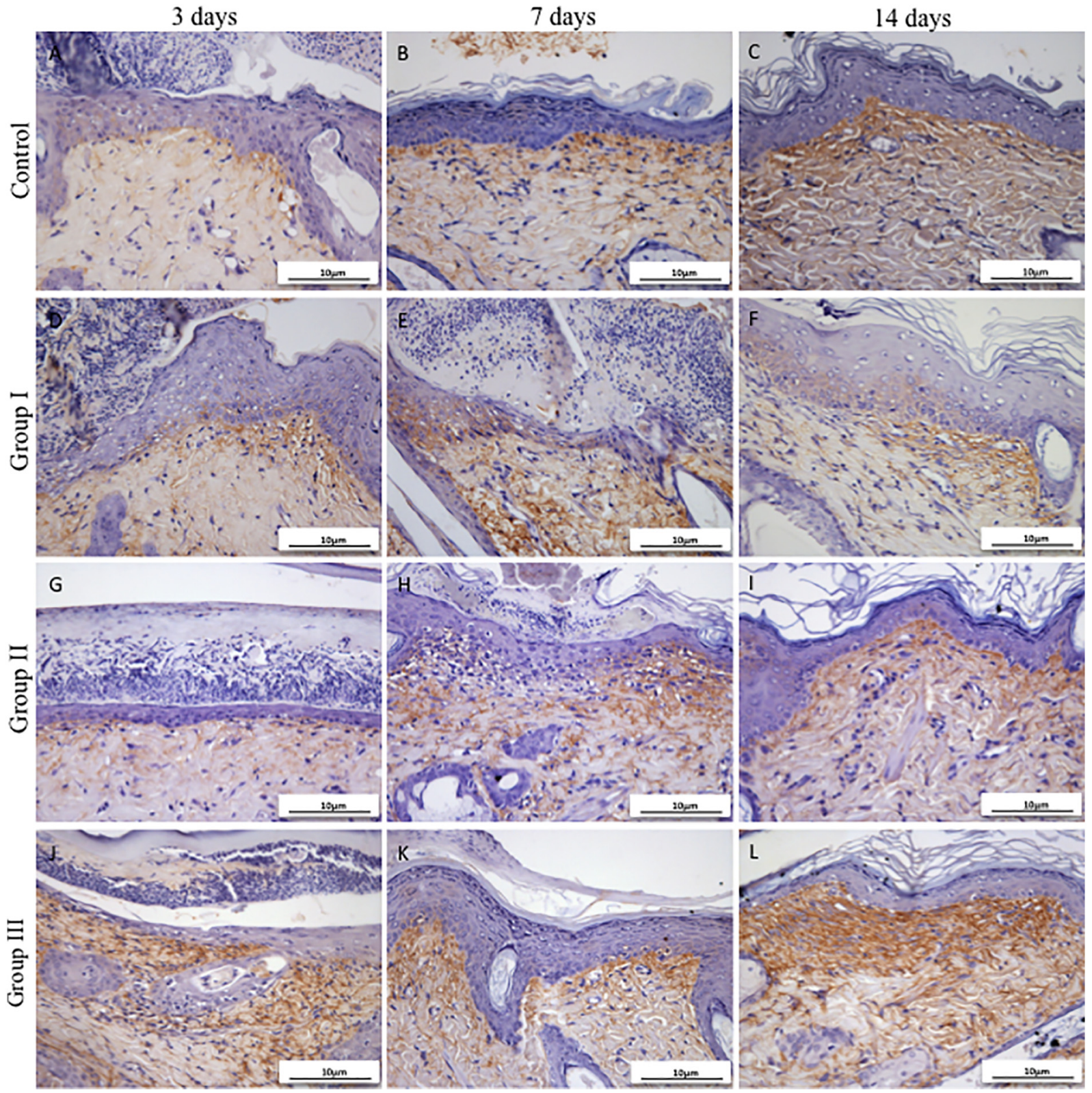

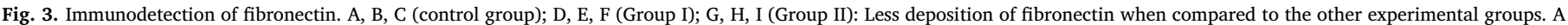
reticular pattern is evidenced; J, K, L (Group III): The highest amount of fibronectin deposition is observed when compared to group II.

early stages of repair, collagen synthesis type III predominates and is then gradually replaced by collagen fibers type I, thicker, stronger, and more prevalent in the normal tissue [26]. Considering these characteristics, laser photobiomodulation have been considered a potentially useful strategy in the treatment of skin lesions as it stimulates the synthesis of collagen type I, thereby enhancing the tissue repair process and promoting connective-tissue stability [27-29].

In the present study, the Groups that solely received laser therapy or in association with the application of Nexfill ${ }^{\mathrm{TM}}$ biocellulose membrane were those with the lowest deposition of type III collagen on the seventh day of the experiment. As the repair process has evolved, there was a tendency of increased collagen deposition III, with an increase in scores for all groups. However, Control, Group II, and Group III had a score of 3 in two or three animals, whereas Group I (laser) hasn't shown any animal with that score - and this result was statistically significant $(\mathrm{p}<0.05)$ compared with the other groups. This result is in accordance with the morphological analysis demonstrating a presence of inflammatory infiltrate as intense on the seventh day of the experiment.
As far as type I collagen is concerned all groups behaved similarly, as there was progress regarding deposition of type I collagen as the repair process evolved. While on the third day of the experiment a few animals showed score 1, on the 14th day all animals in Control, Group I and Group III had a score 3 for collagen I, against only one animal with this score in Group II. When compared to others, regardless of the experimental time Group II showed collagen deposition I significantly lower ( $\mathrm{p}<0.05$ ). Nevertheless, Groups I and III showed no differences in the deposition of collagen I, when compared to Control. The pattern of the fibers has suffered mixed pattern modification (reticular and fibril) to a purely fibril pattern in all groups, demonstrating filling the wound with thicker collagen fibers.

These results appear to suggest that there was no positive influence of therapies applied in the deposition of collagen types I and III. Assessment of results for collagen III also indicates a negative interference of the laser on the seventh day of the experiment. These findings are in line with other authors in that no histological differences were found in the wound healing process when the laser was utilized 

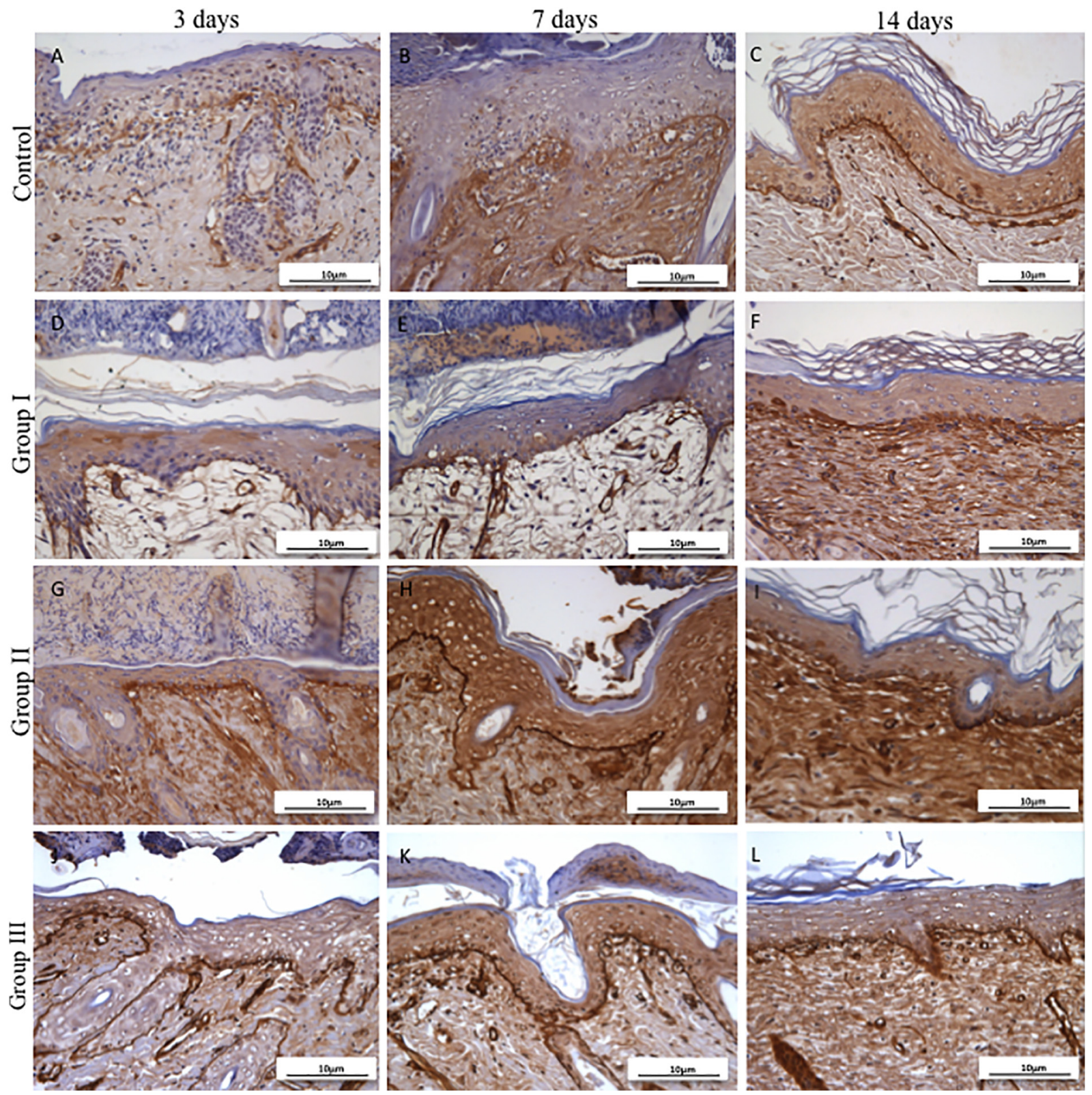

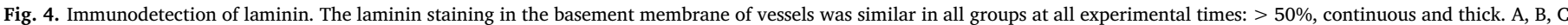

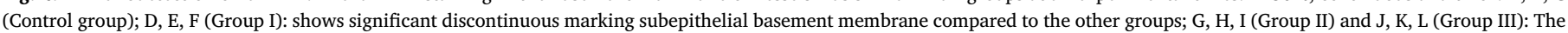
continuity of laminin staining in the subepithelial basement membrane is evidenced.

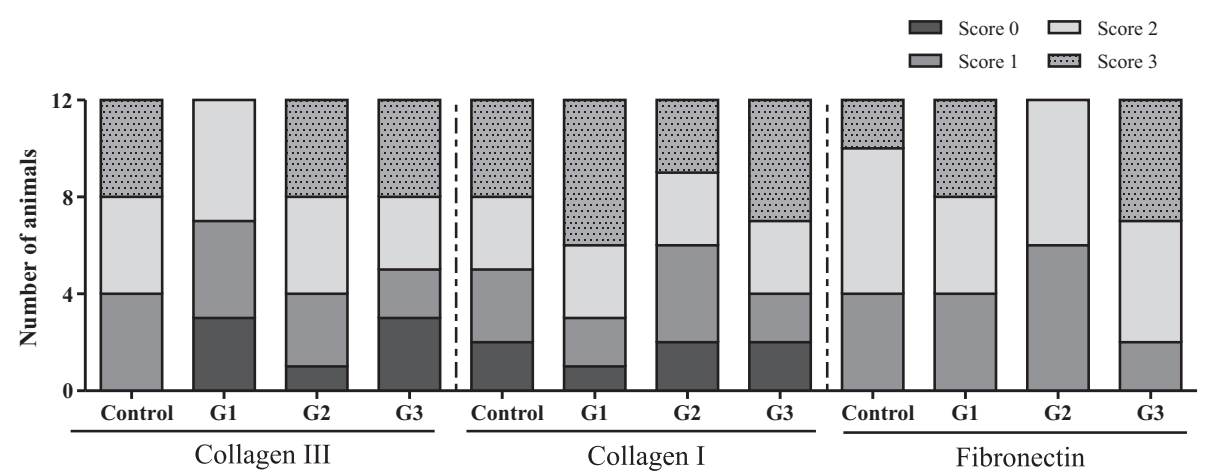

Fig. 5. A comparison between collagen I, collagen III and Fibronectin for all experimental groups regardless experimental time-points. 
Table 3

Percentage (\%) for staining, continuity and thickness for subepithelial basement membrane and basal membrane of vessels.

\begin{tabular}{|c|c|c|c|c|c|c|c|c|}
\hline & Subepithelial b & ment membrane & al membrane of & sels & & & & \\
\hline Groups & Control n (\%) & Group I n (\%) & Group II n (\%) & Group III n (\%) & Control n (\%) & Group II n (\%) & Group II n (\%) & Group III n (\%) \\
\hline \multicolumn{9}{|l|}{$\%$ for staining } \\
\hline$\leq 50 \%$ & - & $1(8,3)$ & - & - & - & - & - & - \\
\hline$>50 \%$ & $12(100)$ & $11(91,7)$ & $12(100)$ & $12(100)$ & $12(100)$ & $12(100)$ & $12(100)$ & $12(100)$ \\
\hline \multicolumn{9}{|l|}{ Continuity } \\
\hline Continuous & $9(75)$ & $4(33,3)$ & $4(33,3)$ & $12(100)$ & $12(100)$ & $12(100)$ & $12(100)$ & $12(100)$ \\
\hline Discontinuous & $3(25)$ & $8(66,7)$ & $8(66,7)$ & - & - & - & - & - \\
\hline \multicolumn{9}{|l|}{ Thickness } \\
\hline Thin & $2(17)$ & $1(8,3)$ & - & - & - & - & - & - \\
\hline Thick & - & - & $4(33,3)$ & $7(58,3)$ & $9(75)$ & $12(100)$ & $12(100)$ & $12(100)$ \\
\hline Mixed & $10(83)$ & $11(91,7)$ & $8(66,7)$ & $5(41,7)$ & $3(25)$ & - & - & - \\
\hline
\end{tabular}

therapeutically $[17,18,25,30,31]$.

When considering laser dosimetry, AlGhamdi et al. [33] proposed an energy density ranging between 0.5 and $4 \mathrm{~J} / \mathrm{cm}^{2}$ as ideal for increasing the proliferation rate of cultured cells. According to Pinheiro et al. [34], when laser light is irradiated on monolayers of cultured cells, maintenance of polarity and consistency may determine the biological results, the same occurring when irradiating an ulcer. Thus, lower doses of irradiation should be applied to mucous membranes, ulcers, or wounds, unlikely intact skin due to stratification. In an extensive review of literature on photobiomodulation, Tuner and Hode [35] described an energy density between 1 and $4 \mathrm{~J} / \mathrm{cm}^{2}$ as the most appropriate in wound repair, at the risk of the laser exert an inhibitory effect on the repair process.

The aforemetioned irradiation protocols was used in researches which reported positive results from laser use in second-degree and third-degree burn repair $[19,32]$ or cutaneous wounds in malnourished animals [23]. On the other hand, unlike observed in the literature $[19,23,32]$ the same total energy density $\left(20 \mathrm{~J} / \mathrm{cm}^{2}\right)$ in the current trial had no positive effects on the repair of second-degree burns. In addition, the divergences of our outcomes might be due to the laser spot size $\left(4 \mathrm{~mm}^{2}\right)$ used in this investigation that was not arranged to cover the entire wound area $\left(400 \mathrm{~mm}^{2}\right)$.

Overall, during experimental trials for all groups there was a higher score for the deposition of collagen I as compared to III. The replacement of collagen type III by type I and a change in fiber pattern which become thicker (fibril) on the last day of the experiment are indicative of organization, maturation, and tensile strength in the healing area. This has occurred in all groups of assessed in a similar manner $[26,29,36]$.

Assessment of laminin staining, performed as per Henriques et al. [37] has demonstrated that the animals receiving laser therapy in isolation (Group I) showed the worst results in the analysis with regard to the pattern of continuity in comparison with Control, Group II, and Group III, and difference was statistically significant $(p<0.05)$. Morphological analysis showed a persistent inflammation in the laserirradiated Group with a persistent edema, dense in the papillary dermis. It is known that the inflammatory process directly affects the ECM dynamics and the extension of the inflammation phase is the main factor causing delayed healing or scar formation [26]. It is likely that this pattern of discontinuity observed in the laser-treated group might be attributed to the presence of inflammatory infiltrate in the analyzed area, thereby resulting in the release of proteolytic enzymes responsible for the degradation of tissue components at the wound site $[38,39]$.

Groups receiving application of the cellulose membrane in isolation or in combination with laser have significantly shown better results than the laser group $(p<0.05)$ in relation to the continuity of laminin staining in the subepithelial basement membrane. The assessment of these results in isolation suggests that the use of cellulose biomembrane appears to favor the deposition of this protein. This result may be related to its nanostructural configuration, which prevents contamination of the wound area, restricts fluid loss in a unique configuration that mimics the properties of the ECM by binding to water and behaving as a hydrogel that integrates with tissue allowing cell migration through the structure $[9,10]$. Regarding the laminin expression in vascular basement membrane, all groups have shown similar results.

It has been noted during the immunohistochemical analysis the expression of fibronectin in the epithelial tissue in several regions. A number of works in the literature has implied that keratinocytes are cells that secrete and deposit fibronectin in the pericellular matrix [40-42], thus suggesting the important role of this glycoprotein also in intercellular adhesion of the epithelial tissue.

Considering the important role fibronectin plays for the repair process, therapies that may trigger an increase in deposition can be helpful allies in this process, especially when dealing with wounds that pose some difficulty or show delay in healing. However, the present study has failed to verify a bio-stimulant effect of laser on fibronectin deposition in the wound area. Groups I, II, and III showed the fibronectin expression predominantly discontinuous near the basement membrane in comparison with the Control group, with no statistical significance, nonetheless.

\section{Conclusion}

In concluding, in this study we haven't found any beneficial effect when the laser was utilized in isolation (Group I) in the process of collagen deposition III and I; similarly, no favorable effect was found in collage patterns (fibril and/or reticular), acceleration of repair in induced burn injury in the dorsum of rats.

There was a trend towards a greater deposition of type III collagen in the wounds treated with a biocelulose membrane in isolation (Group II) or with laser therapy (Group III), as early as seven days afterwards when these groups were compared with their laser-treated counterparts (Group I). The continuity of the laminin staining in the subepitelial layer of the membrane in Groups II and III suggests that the cellulose membrane either in isolation or in combination with the laser has favored re-epithelialization in second-degree burns.

However, further research into the use of the cellulose biomembrane in burn repair is clearly needed in order to assure the beneficial effects for a prompt re-epithelialization. The application of the biocellulose membrane in isolation has ultimately reduced the wound covering by fibronectin.

\section{Acknowledgments}

The authors greatfully acknowledge financial support by the Conselho Nacional de Pesquisa (CNPq, 308595/2016-5), Brazil.

\section{References}

[1] S.C. Nunez, C.M. França, D.F.T. Silva, G.E.C. Nogueira, R.A. Prates, M.S. Ribeiro, 
The influence of red laser irradiation timeline on burn healing in rats, Lasers Med. Sci. 28 (2012) 633-641.

[2] M.D. Peck, Epidemiology of burns throughout the world. Part I: distribution and risk factors, Burns 37 (2011) 1087-1100.

[3] J.R. Saffle, Closure of the excised burn wound: temporary skin substitutes, Clin. Plast. Surg. 36 (2009) 627-641.

[4] M.C. Ferreira, A.O. Paggiaro, C. Isaac, N. Teixeira Neto, G.B. Dos Santos, Substitutos cutâneos: conceitos atuais e proposta de classificação, Rev. Bras Cir Plást 26 (2011) 696-702.

[5] M. Held, J. Rothenberger, A.S. Engelke, D.S. Tolzmann, B.J. Esfahani, H.E. Schaller, A. Rahmanian-Schwarz, Evaluation of commonly used temporary skin dressings and a newly developed collagen matrix for treatment of superficial wounds, Adv. Skin Wound Care 28 (2015) 551-554.

[6] R.R.J. Guirro, E.C.O. Guirro, C.C. Martins, F.R. Nunes, Analysis of low-level laser radiation transmission in occlusive dressings, Photomed. Laser Surg. 28 (2010) $459-463$.

[7] A.G. Haddad, A.G. Giatsidis, D.P. Orgill, E.G. Halvorson, Skin substitutes and Bioscaffolds: Temporary and Permanent Coverage, Clin. Plast. Surg. 44 (3) (2017 Jul) 627-634.

[8] G.F. Picheth, C.L. Pirich, M.R. Sierakowski, M.A. Woehl, C.N. Sakakibara, C.F. de Souza, A.A. Martin, R. da Silva, R.A. de Freitas, Bacterial cellulose in biomedical applications: a review, Int. J. Biol. Macromol. 3 (104) (2017) 97-106.

[9] Pecoraro, et al., Bacterial cellulose from Glucanacetobacter xylinus: preparation, properties and applications, Monomers, Polymers and Composites from Renewable Resources, First ed., Elsevier, Oxford, 2008.

[10] N. Petersen, P. Gatenholm, Bacterial cellulose-based materials and medical devices: current state and perspectives, Appl. Microbiol. Biothecnol. 91 (2011) 1277-1286.

[11] A.J. Hussein, A. A, M.A. Falih, A.N. Hassan, Effects ofa low level laser onthe acceleration of wound healing in rabbits, N. Am. J. Med. Sci. 3 (2011) 193-197.

[12] A.M. Rocha Junior, R.G. Oliveira, R.E. Farias, L.C.F. Andrade, F.M. Aarestrup, Modulation of fibroblast proliferation and inflammatory response by low-intensity laser therapy in tissue repair process, An. Bras. Dermatol. 81 (2006) 150-156.

[13] T.N. Demidova-Rice, E.V. Salomatina, A.N. Yaroslavsky, I.M. Herman, M.R. Hamblin, Low-level light stimulates excisional wound healing in mice, Lasers Surg. Med. 39 (2007) 706-715.

[14] I.C.V. Decastro, S.C.P. Oliveira-Sampaio, Monteiro JSDC, Ferreira MFL, J.N. Santos, Pinheiro ALB, Evaluation of the effect of laser radiation on fibroblast proliferation in repair of skin wounds of rats with iron deficiency anemia, Proc. SPIE 7887 (2011) 1-6.

[15] S. Martu, C. Amalinei, M. Tatarciuc, M. Rotaru, O. Potarnichie, L. Liliac, et al., Healing process and laser therapy in the superficial periodontum: a histological study, Romanian J. Morphol. Embryol. 53 (2012) 111-116.

[16] F. Heu, C. Forster, B. Namer, A. Dragu, W. Lang, Effect of low-level laser therapy on blood flow and oxygen- hemoglobin saturation of the foot skin in healthy subjects: a pilot study, Laser Ther. 22 (2013) 21-30.

[17] M. Bayat, M.M. Vasheghani, N. Razavi, S. Taheri, M. Rakhshan, Effect of low-level laser therapy on the healing of second-degree burns in rats: a histology:ical and microbiological study, J. Photochem. Photobiol. B Biol. 78 (2005) 171-177.

[18] F.A.H. Al-Watban, M.D. Delgado, Burn healing with a diode laser: $670 \mathrm{~nm}$ at different doses as compared to a placebo group, Photomed. Laser Surg. 23 (2005) $245-250$.

[19] G.C.S. Meireles, J.N. Santos, P.O. Chagas, A.P. Moura, A.L.B. Pinheiro, Effectiveness of laser photobiomodulation at 660 or 780 nanometers on the repair of third-degree burns in diabetic rats, Photomed. Laser Surg. 26 (2008) 47-54.

[20] E.C.O. Guirro, M.I.L. Montebelo, B.A. Bortot, M.A.C.B. Torres, M.L.O. Polacow, Effect of laser $(670 \mathrm{~nm})$ on healing of wounds covered with occlusive dressing: a histologic and biomechanical analysis, Photomed. Laser Surg. 28 (2010) 629-634.

[21] M.D.M. Dantas, et al., Improvement of dermal burn healing by combining sodium alginate/chitosan-based films and low level laser therapy, J. Photochem. Photobiol.
B 105 (2011) 51-59.

[22] T.N. Meyer, A.L.A. Silva, A standard burning model using rats, Acta Cir. Bras. 14 (1999) 1-4.

[23] A.L.B. Pinheiro, A.L.B. Vieira, D.S. Almeida, G.C.S. Meireles, C.M. Carvalho, J.N. Santos, Phototherapy improves healing of cutaneous wounds in nourished and undernourished Wistar rats, Braz. Dent. J. 15 (2004) 21-28.

[24] J.M. Moraes, et al., Anti-inflammatory effect of low-intensity laser on the healing of third-degree burn wounds in rats, Lasers Med. Sci. 28 (2013) 1169-1176.

[25] A. Schlager, P. Kronberger, F. Petschke, H. Ulmer, Low-power laser light in the healing of burns: a comparision between two different wavelengths (635 $\mathrm{nm}$ and $690 \mathrm{~nm}$ ) and a placebo group, Lasers Surg. Med. 27 (2000) 39-42.

[26] E.A. Gantwerker, D.B. Hom, Skin: histology and physiology of wound healing, Clin. Plast. Surg. 39 (2012) 85-97.

[27] A.R.A.P. Medrado, L.S. Pugliese, S.R.A. Reis, Z.A. Andrade, Influence of low level laser therapy on wound healing and its biological action upon myofibroblasts, Lasers Surg. Med. 32 (2003) 239-244.

[28] L.S. Pugliese, A.L. Medrado, S.R.A. Reis, Z.A. Andrade, The influence of low-level laser therapy on biomodulation of collagen and elastic fibers, Pesqui Odontol. Bras. 17 (2003) 307-313.

[29] H. Liu, Y. Dang, Z. Wang, X. Chai, Q. Ren, Laser induced collagen remodeling: a comparative study in vivo on mouse model, Lasers Surg. Med. 40 (2008) 13-19.

[30] G. Anneroth, G. Hall, H. Rydén, L. Zettergvist, The effect of low-energy infra-red laser radiation on wound healing in rats, Br. J. Oral Maxillofac. Surg. 26 (1988) 12-17.

[31] G. Hall, G. Anneroth, T. Schennings, L. Zettergvist, H. Ridén, Effect of low level energy laser irradiation on wound healing. An experimental study in rats, Swed. Dent. J. 18 (1994) 29-34.

[32] E.T. Trajano, L.A. da Trajano, M.A. Dos Santos, N.G. Venter Silva, L.C. de Porto, A. de Fonseca, A. Monte-Alto-Costa, Low-level red laser improves healing of seconddegree burn when applied during proliferative phase, Lasers Med. Sci. 30 (2015) 297-304.

[33] K.M. AlGhamdi, A. Kumar, N.A. Moussa, Low-level laser therapy: a useful technique for enhancing the proliferation of various cultured cells, Lasers Med. Sci. 27 (2012) 237-249.

[34] A.L.B. Pinheiro, A. Brugnera Junior, F.A.A. Zanin, Aplicação do laser na odontologia, First ed., GEN, Santos, São Paulo, 2010.

[35] J. Tuner, L. Hode, It's all in the parameters: a clinical analysis of some well-known negative studies on low-level laser therapy, J. Clin. Laser Med. Surg. 16 (1998) 245-248.

[36] R.D. Novaes, et al., The energy density of laser light differentially modulates the skin morphological reorganization in a murine model of healing by secondary intention, Int. J. Exp. Pathol. 95 (2013) (2013) 138-146.

[37] A.C.G. Henriques, M.G. Vasconcellos, H.C. Galvão, L.B. De Souza, R.A. Freitas, Comparative analysis of the immunohistochemical expression of collagen IV, MMP9 and TIMP-2 in odontogenic cysts and tumors, Oral Surg. Oral Med. Oral Pathol. Oral Radiol. Endod. 112 (2011) 468-475.

[38] L.B. Quinderé, C.F.W. Nonaka, L.B. Souza, L.P. Pinto, Expressão imunohistoquímica de colágeno IV, tenascina-C e fibronectina em lesões centrais e periféricas de células gigantes, Rev. Inst. Ciênc Saúde. 26 (2008) 226-231.

[39] C.A.S. Gurgel, et al., Immunolocalisation of laminin-1 in keratocystic odontogenic tumors, Acta Histochem. 112 (2010) 624-629.

[40] M. Kubo, D.A. Norris, S.E. Howell, S.R. Ryan, R.A. Clark, Human keratinocytes synthesize, secrete, and deposit fibronectin in the pericellular matrix, J. Invest. Dermatol. Jun 82 (6) (1984) 580.

[41] A. Linnala, E. Balza, L. Zardi, I. Virtanen, Human amnion epithelial cells assemble tenascins and three fibronectin isoforms in the extracellular matrix, FEBS Lett. 8 (317) (1993) 74-78.

[42] M. Kubo, et al., Immunoelectron microscopic localization of fibronectin in cultured human keratinocytes, Arch. Dermatol. Res. 286 (1994) 448-454. 